\title{
Meta-análise do impacto da fibra em detergente neutro sobre o consumo, a digestibilidade e o desempenho de vacas leiteiras em lactação ${ }^{1}$
}

\author{
André Soares de Oliveira ${ }^{2}$, Edenio Detmann ${ }^{3}$, José Maurício de Souza Campos ${ }^{3}$, Douglas dos \\ Santos Pina ${ }^{4}$, Shirley Motta de Souza ${ }^{4}$, Marcone Geraldo Costa ${ }^{4}$ \\ 1 Apoio FAPEMIG e CNPq. \\ 2 Instituto de Ciências Agrárias e Ambientais, Universidade Federal de Mato Grosso, Campus de Sinop, Sinop, MT. \\ ${ }^{3}$ Departamento de Zootecnia, Universidade Federal de Viçosa, Viçosa, MG. Pesquisador do CNPq e do INCT - Ciência Animal. \\ 4 Programa de Pós-Graduação em Zootecnia, Universidade Federal de Viçosa, Viçosa, MG.
}

RESUMO - Avaliaram-se os efeitos das características químicas e da digestibilidade in vivo da FDN (DFDN) sobre o consumo, a digestibilidade e o desempenho de vacas leiteiras em confinamento utilizando-se meta-análise a partir de 285 observações de seis experimentos. Utilizaram-se dados de animais alimentados com dietas à base de silagem de milho (n = 213) ou cana-de-açúcar $(\mathrm{n}=72)$. Apesar do menor teor de FDN da cana-de-açúcar $(45,27 \%$ da MS) em relação à silagem de milho (54,48\%), observaram-se menores consumos de MS e FDN, que refletiram em menor produção de leite. Verificou-se maior redução no comsumo de matéria seca (kg/dia) com aumento do teor de FDNf (FDN de forragem, \% da MS) em dietas com canade-açúcar (332,4 g de MS para cada 1\% no teor de FDNf) em relação à silagem de milho (96 g de MS para cada $1 \%$ no teor de FDNf). O maior efeito de repleção ruminal da FDN da cana-de-açúcar deve-se à fração indigestível, majoritária, apesar da maior taxa de degradação da fração potencialmente degradável da FDN em relação à silagem de milho. A produção de leite não-corrigida (PL) e corrigida para 4\% de gordura (PLC) e o teor de proteína do leite reduziram linearmente com o aumento no teor de FDNf, independentemente da fonte de forragem. Porém, a PL e PLC não foram afetadas pelo nível de FDNnf (FDN de não-forragem). Os consumos de MS, FDN e NDT e o teor de gordura no leite reduziram linearmente com aumento na relação lignina:FDN, com maior amplitude em dietas à base de cana-de-açúcar em relação à silagem de milho. O consumo de MS, a produção de leite e a produção de leite corrigida reduziram linearmente e na mesma magnitude entre as fontes de forragens, com o aumento na DFDN da dieta. O efeito do teor FDN e lignina sobre o consumo, a digestibilidade e o desempenho animal depende da fonte utilizada.

Palavras-chave: cana-de-açúcar, repleção ruminal, silagem de milho

\section{Meta-analysis of the impact of neutral detergent fiber on intake, digestibility and performance of lactating dairy cows}

\footnotetext{
ABSTRACT - It was evaluated the effects of the chemical characteristics and in vivo NDF digestibility (IVNDFD) on intake, digestibility and performance of dairy cows in fedlot by using a meta-analysis procedure from 285 observations of six experiments. It was used data of animals fed diets based on corn silage $(n=213)$ or sugarcane $(n=72)$. Despite the lower NDF content of sugarcane $(45.27 \%$ of DM) compared to corn silage $(54.48 \%)$, it was noted lower intakes of dry matter (DMI) and NDF, which responded with a lower milk yield. It was observed a greater reduction in DMI (kg/day) with the increase of NDFf (NDF forage, \% DM) in sugarcane diets (332.4 g of DM for each 1\% of NDFf) in relation to corn silage (96 g of DM for each $1 \%$ of NDFf). The greatest effect of ruminal repletion of sugar cane NDF is caused by the indigestible fraction, majoritary, despite the highest degradation rate of NDF potentially degradable fraction in relation to corn silage. Milk production not corrected (MP) and MP corrected to 4\% fat (MPC) and the content of milk protein decreased linearly with the increase of NDFf content, regardless of the forage source. However, MP and MPC were not affected by NDFnf (non-forage NDF) level. Intakes of DM, NDF, TDN and milk fat content decreased linearly with increase in the lignin:NDF ratio, with greater amplitude in sugarcane based diets in relation to silage corn. Dry matter intake, MP and MPC reduced linearly and at the same magnitude among forage sources, with the increase in NDFD of the diet. The effect of NDF and lignin on intake, digestibility and animal performance depend upon the source used.
}

Key Words: corn silage, ruminal retention, sugarcane

Recebido em 30/10/2009 e aprovado em 27/8/2010.

Correspondências devem ser enviadas para: andresoli@uol.com.br 


\section{Introdução}

Os níveis de fibra em detergente neutro (FDN) em dietas para vacas em lactação são normalmente ajustados visando manter o funcionamento normal do rúmen, otimizar o consumo e a digestibilidade dietética, bem como o desempenho bioeconômico dos animais.

Devido às suas características químicas e físicas peculiares, a FDN compreende à fração do alimento insolúvel em meio neutro lentamente degradável (em comparação ao conteúdo celular) e ou indegradável, as quais respondem pela porção que ocupa espaço no trato digestivo dos ruminantes. Em razão disso, em pesquisas pioneiras estabeleceu-se a fração fibrosa insolúvel (FDN) como o componente do alimento de maior influência sobre o consumo e a digestibilidade (Van Soest, 1965; Smith et al., 1972), estimulando-se o desenvolvimento de modelos de predição de consumo e digestibilidade utilizando o teor de FDN como preditor único (Mertens, 1987). Todavia, em diversos estudos posteriores evidenciou-se que seu uso como preditor único talvez seja inadequado, em razão da elevada heterogeneidade química e física entre as fontes de FDN (Allen, 1996; Allen, 2000; Vasquez \& Smith, 2000; Krizsan \& Randby, 2007).

Fatores como a composição química da FDN (conteúdo e tipo de lignina e sua interação físico-química com os demais componentes); dimensão das frações potencialmente degradável (FDNpd) e indegradável (FDNi); tamanho inicial, densidade e fragilidade das partículas; bem como a atividade da microbiota ruminal, afetam diretamente os parâmetros das dinâmicas de degradação e trânsito pelo trato digestório, os quais modulam os efeitos da FDN sobre o consumo e digestão de nutrientes (Waldo et al., 1972; Allen \& Mertens, 1988; Allen, 1996; Paulino et al., 2006; Lund et al., 2007). Fontes com o mesmo teor de FDN podem apresentar respostas diferentes, da mesma forma que fontes com maior teor de FDN não necessariamente implicam em respostas mais negativas sobre o consumo e a digestão.

Assim, para avaliação dos efeitos da FDN, discriminações devem ser feitas quanto à natureza e características das fontes. Em geral, a FDN oriunda de forragens apresenta maior repleção ruminal do que aquela oriunda de fontes não-forragens. Além disso, no grupo de forrageiras, diferenças entre espécies, maturidade, condições climáticas, etc, implicam variações no teor e nas características químicas e físicas da FDN.

Porém, o isolamento dos efeitos da FDN sobre a digestibilidade e o desempenho animal é complexo em razão de diversos fatores de confudimento encontrados mesmo em experimentos adequadamente conduzidos. Diferenças na relação volumoso:concentrado, na fonte de amido disponível no rúmen e no teor de FDN entre as dietas constituem fatores de confundimento comumente observados (Oba \& Allen, 1999). O controle dos fatores de confundimentos pode ser obtido através de estudos de meta-análise, utilizando-se procedimentos estatísticos adequados (Oba \& Allen, 1999).

Neste contexto, propôs-se avaliar os efeitos das características químicas e da digestibilidade in vivo da FDN sobre o consumo, digestibilidade dos nutrientes e desempenho de vacas em lactação confinadas utilizando informações oriundas de seis experimentos.

\section{Material e Métodos}

Os dados foram originados de seis experimentos com vacas em lactação confinadas, totalizando 285 observações. Todos os experimentos foram conduzidos segundo delineamento em quadrado latino $4 \times 4$, replicados ou não, com períodos experimentais variando entre 14 a 21 dias e utilizando-se silagem de milho ( $\mathrm{n}=213$ ) ou cana-de-açúcar ( $\mathrm{n}=72$ ), como fonte de única de forragem (Assis, 2005; Costa et al., 2005; Pina et al., 2006; Oliveira et al., 2007; Souza, 2007). As fontes de FDN não-forragem utilizadas nos experimentos foram: casca de café, casca de soja, casca de caroço de algodão, farelo de glúten de milho (refinasil) e farelo de trigo.

Analisaram-se os efeitos dos teores dietéticos de FDN, de FDN de forragem (FDNf), de FDN de não-forragem (FDNnf), da relação lignina:FDN e da digestibilidade in vivo da FDN (DFDN) sobre o consumo de MS (CMS), consumo de FDN (CFDN), teor e consumo de nutrientes digestíveis totais (NDT), produção e composição do leite. Os dados foram posteriormente estratificados em função da fonte de FDN oriunda de foragem (cana-de-açúcar ou silagem de milho).

Inicialmente, os dados foram analisados segundo:

$Y_{i j k l}=\mu+E_{i}+Q_{(i) j}+A_{(i j) k}+P_{(i j) l}+\varepsilon_{i j k l}$ em que: $\mathrm{Y}_{\mathrm{ijkl}}=$ resposta variável; $\mu=$ constante geral; $\mathrm{E}_{\mathrm{i}}=$ efeito fixo do experimento $\mathrm{i}$, sendo; $\mathrm{Q}_{(\mathrm{i}) \mathrm{j}}=$ efeito aleatório de quadrado latino j aninhado ao experimento i; $\mathrm{A}_{(\mathrm{ij}) \mathrm{k}}=$ efeito aleatório do animal $\mathrm{k}$ aninhado ao quadrado latino j dentro do experimento i; $\mathrm{P}_{(\mathrm{ij}) \mathrm{l}}=$ efeito aleatório do período $\mathrm{l}$ aninhado ao quadrado latino j dentro do experimento i; e $\varepsilon_{\mathrm{ijkl}}=$ erro aleatório, não observável, pressuposto NID $\left(0, \sigma^{2}\right)$

Previamente às análises, as variâncias residuais de cada experimento foram comparadas pelo teste de Bartlett, verificando-se condição de homocedasticidade $(\mathrm{P}>0,05)$.

A partir das funções estimáveis obtidas por intermédio do modelo descrito em (1), as observações foram ajustadas 
em relação aos efeitos aninhados de quadrado latino, período e animal.

Posteriormente, as observações ajustadas foram analisadas por intermédio de regressão linear, procedendo-se à estratificação das observações no modelo de acordo com a fonte de FDN de forragem (cana-de-açúcar ou silagem de milho) a partir do uso de variável Dummy (Drapper \& Smith, 1966), segundo o modelo básico:

$\hat{Y}=\hat{\beta_{0}}+\hat{\beta_{1}} \times D+\hat{\beta_{2}} \times X+\hat{\beta_{3}} \times(D \times X)$

em que: $\hat{Y}=$ resposta estimada; $\hat{\beta}_{0}=$ estimativa do intercepto da função; $\hat{\beta_{1}}, \hat{\beta_{2}}, \hat{\beta_{3}}=$ estimativas dos coeficientes de regressão; $D$ = variável Dummy relativa do efeito de fonte de FDN de forragem, em que $\mathrm{D}=0$ para silagem de milho e $\mathrm{D}=1$ para cana-de-açúcar; e $\mathrm{X}$ = variável independente.

Todas as análises estatísticas foram conduzidas utilizando-se o programa SAS (PROC MIXED, PROC GLM e PROC REG) adotando-se 0,05 como nível crítico de probabilidade para o erro tipo I.

\section{Resultados e Discussão}

A amplitude observada entre as variáveis permitiu avaliações representativas do impacto da fibra em detergente neutro sobre o consumo, digestibilidade e desempenho de vacas leiteiras (Tabela 1). Diferenças foram verificadas entre dietas contendo silagem de milho e cana-de-açúcar, notadamente sobre o consumo de matéria seca e fibra em detergente neutro, os quais afetam diretamente o desempenho animal. Os consumos de matéria seca e fibra em detergente neutro foram menores $(\mathrm{P}<0,05)$ em dietas contendo cana-de-açúcar em relação à silagem de milho. Este comportamento apresenta-se como a principal limitação para o uso da cana-de-açúcar como fonte forragem para ruminantes, com reflexos na menor $(\mathrm{P}<0,05)$ produção de leite.

Apesar de a cana-de-açúcar apresentar menor $(\mathrm{P}<0,05)$ teor de FDN que a silagem de milho, alguns autores atribuem reduções no consumo à menor digestibilidade da FDN e principalmente à menor taxa de digestão da fração fibrosa potencialmente digestível, que aumenta o tempo de retenção da digesta no retículo-rúmen e reduz a taxa de passagem pelo trato gastrintestinal (Pereira et al., 2000; Magalhães, 2006). No entanto as razões do maior efeito de repleção ruminal da FDN da cana-de-açúcar ainda não estão bem esclarecidas.

Para eliminar os efeitos negativos da maior repleção ruminal sobre o desempenho produtivo, faz-se necessário aumentar a quantidade de alimentos concentrados na dieta, em relação às dietas com silagem de milho, o que sob aspecto econômico pode não ser conveniente (Costa, 2004; Oliveira, 2005).

Em razão do maior efeito de repleção ruminal, os valores de consumo de FDN das dietas expresso em relação ao peso corporal, diferem entre as fontes de forragem utilizadas com valor médio de 1,32\% para silagem de milho e 0,94\% para

Tabela 1 - Estatísticas descritivas e nível de probabilidade para o erro tipo I (Valor- $P$ ) associado ao efeito de fonte de forragem

\begin{tabular}{|c|c|c|c|c|c|c|c|c|c|c|}
\hline \multirow[t]{2}{*}{ Item } & \multicolumn{4}{|c|}{ Silagem de milho } & \multicolumn{4}{|c|}{ Cana-de-açúcar } & \multirow[t]{2}{*}{ Valor- $P$} & \multirow[t]{2}{*}{ CV (\%) } \\
\hline & Média & Min & Max & $\mathrm{n}$ & Média & Min & Max & $\mathrm{n}$ & & \\
\hline PL (kg) & 28,84 & 13,80 & 33,5 & 213 & 18,68 & 8,96 & 22,80 & 72 & $<0,0001$ & 15,0 \\
\hline GOR (\%) & 3,71 & 2,86 & 4,69 & 213 & 3,57 & 2,31 & 4,20 & 72 & 0,0030 & 9,1 \\
\hline PTN (\%) & 3,30 & 2,83 & 4,08 & 213 & 3,72 & 3,37 & 4,03 & 72 & $<0,0001$ & 5,3 \\
\hline CMS (kg) & 19,60 & 16,02 & 22,77 & 213 & 18,71 & 14,45 & 22,03 & 72 & $<0,0001$ & 8,3 \\
\hline CFDN (\% peso corporal) & 1,32 & 0,71 & 2,11 & 213 & 0,94 & 0,57 & 1,66 & 72 & $<0,0001$ & 19,2 \\
\hline CNDT (kg) & 12,64 & 8,95 & 16,70 & 213 & 12,57 & 8,82 & 15,85 & 72 & 0,7218 & 11,3 \\
\hline DFDN (\%) & 46,23 & 17,69 & 68,21 & 213 & 31,86 & 10,66 & 48,77 & 72 & $<0,0001$ & 22,1 \\
\hline \multirow[t]{2}{*}{ NDT (\%) } & 64,73 & 38,38 & 85,90 & 213 & 67,28 & 43,24 & 81,62 & 72 & 0,0048 & 10,1 \\
\hline & \multicolumn{10}{|c|}{ Característica dietética } \\
\hline V:C (\%) & 56,76 & 44,00 & 65,00 & 18 & 45,00 & 40,00 & 60,00 & 6 & - & - \\
\hline CNF (\%) & 33,54 & 25,43 & 43,29 & 18 & 46,06 & 43,58 & 48,54 & 6 & - & - \\
\hline FDNF (\% MS) & 54,48 & 45,74 & 62,34 & 18 & 45,27 & 42,29 & 48,30 & 6 & - & - \\
\hline Lig:FDNF (\%) & 8,42 & 5,13 & 14,12 & 18 & 14,75 & 12,62 & 16,87 & 6 & - & - \\
\hline
\end{tabular}

PL = produção de leite; PLC = produção de leite corrigida para 4\% de gordura; GOR = teor de gordura do leite; PTN = teor de proteína do leite; CMS = consumo de matéria seca; CFDN = consumo de FDN; CNDT = consumo de NDT; DFDN = digestibilidade da FDN; NDT = teor dietético de NDT; F:C = relação volumoso:concentrado; FDNf = teor dietético de FDN oriunda de forragem; FDNnf = teor ditético de FDN oriunda de fontes não-forragens; Lig:FDN = relação lignina:FDN na dieta; CNF carboidratos não-fibrosos; FDNF = teor de FDN na forragem; Lig:FDNF = relação Lig:FDN na forragem. 
cana-de-açúcar. Este comportamento apresenta implicações práticas importantes, pois o consumo de FDN tem sido usado para predição da fração ótima de forragem em dietas para vacas leiteiras utilizando-se valor fixo de 1,1 ou 1,2\% do peso corporal (Mertens, 1987). Assim, a utilização deste fator possivelmente irá superestimar a fração de forragem em dietas contendo cana-de-açúcar. Desta forma, discriminações deverão ser feitas quanto à fonte para utilização eficaz da FDN nos sistemas de avaliação e balanceamento de dietas.

Nota-se que a despeito da menor DFDN, o teor de NDT nas dietas com cana-de-açúcar foi maior $(\mathrm{P}<0,05)$ em relação à silagem de milho, possivelmente, em razão da maior fração de carboidratos não-fibrosos. As frações de CNF são reconhecidas por apresentar alto coeficiente de digestibilidade verdadeiro (95 a 98\%) mesmo em condições tropicais (Van Soest, 1994; Detmann et al., 2006).

Observa-se que o impacto da fibra sobre o consumo de matéria seca, digestibilidade e desempenho animal varia em função da forma com que essa expressa (FDN, FDNf, FDNnf) e da fonte utilizada. O aumento no teor de FDN na dieta causou aumento $(\mathrm{P}<0,05)$ no consumo de matéria seca (kg/dia) na mesma magnitude (19,9 gramas de MS para cada 1\% no teor de FDN) entre as forragens (Tabela 2). Contrariamente, quando discriminado em FDNf observouse maior redução no CMS ( $\mathrm{kg} /$ dia) com aumento do teor de FDNf em dietas com cana-de-açúcar (332,4 gramas de MS para cada $1 \%$ no teor de FDNf) em relação à silagem de milho (96 gramas de MS para cada 1\% no teor de FDNf), pois permitiu isolar as diferenças quanto ao efeito de repleção ruminal entre a frações FDN das forragens (Tabela 3). Todavia, o consumo de matéria seca (kg/dia) nas dietas com silagem de milho não foi afetado pelo aumento da FDNnf, mas aumentou $(\mathrm{P}<0,05)$ nas dietas com cana-de-açúcar (201,3 gramas de MS para cada 1\% no teor de FDNnf) (Tabela 4). Este comportamento heterogêneo observado entre as fontes de FDN é reflexo das diferenças químicas e físicas entre as mesmas, o que reforça os argumentos

Tabela 2 - Estimativas dos parâmetros de regressão ( $\mathrm{Y}=\mathrm{B}_{0}+\mathrm{B}_{1} \cdot \mathrm{FOR}+\mathrm{B}_{2} \cdot \mathrm{X}+\mathrm{B}_{3}$.X. FOR) do efeito do teor de FDN na dieta sobre o consumo, digestibilidade e desempenho de vacas leiteiras recebendo dietas à base de silagem de milho ou cana-de-açúcar

\begin{tabular}{|c|c|c|c|c|c|}
\hline \multirow[t]{2}{*}{ Variável dependente (Y) } & \multicolumn{4}{|c|}{ Estimativa dos parâmetros } & \multirow[t]{2}{*}{$\mathrm{R}^{2}$} \\
\hline & $B_{0}$ & $B_{1}$ & $B_{2}$ & $B_{3}$ & \\
\hline CMS (kg/d) & 18,5676 & & 0,0199 & & 0,0069 \\
\hline CMS (\%peso/d) & 3,2711 & & & & - \\
\hline CFDN (kg/d) & & & 0,1787 & & 0,4672 \\
\hline CFDN (\% peso/d) & & & 0,0294 & & 0,4948 \\
\hline DFDN (\%) & 42,6024 & & & & - \\
\hline NDT (\% MS) & 65,3424 & & & & - \\
\hline CNDT $(\mathrm{kg} / \mathrm{d})$ & 13,6834 & & $-0,02612$ & & 0,0159 \\
\hline PL (kg/d) & 13,1504 & & 0,2511 & & 0,1539 \\
\hline $\operatorname{PLC}(\mathrm{kg} / \mathrm{d})$ & 14,7034 & & 0,1898 & & 0,1261 \\
\hline Gor $(\%)$ & 3,6705 & & & & - \\
\hline Ptn (\%) & 4,2992 & $-0,5668$ & $-0,0229$ & 0,0225 & 0,6231 \\
\hline
\end{tabular}

FOR representa variável dummy (silagem de milho = 0, cana-de-açúcar $=1$ ).

CMS = consumo de matéria seca; CFDN = consumo de fibra em detergente neutro; DFDN = digestibilidade da FDN; NDT = nutrientes digestíveis totais; CNDT = consumo de NDT; PL = produção de leite; PLC = produção de leite corrigida para 3,5\% de gordura; Gor = teor de gordura do leite; Ptn = teor de proteína do leite.

Tabela 3 - Estimativas dos parâmetros de regressão ( $\mathrm{Y}=\mathrm{B}_{0}+\mathrm{B}_{1}$.FOR $+\mathrm{B}_{2} \cdot \mathrm{X}+\mathrm{B}_{3} \cdot \mathrm{X}$. FOR) do efeito do teor de FDNf na dieta (\%) sobre o consumo, digestibilidade e desempenho de vacas leiteiras recebendo dietas à base de silagem de milho ou cana-de-açúcar

\begin{tabular}{|c|c|c|c|c|c|}
\hline \multirow[t]{2}{*}{ Variável dependente (Y) } & \multicolumn{4}{|c|}{ Estimativa dos parâmetros } & \multirow[t]{2}{*}{$\mathrm{R}^{2}$} \\
\hline & $B_{0}$ & $B_{1}$ & $B_{2}$ & $B_{3}$ & \\
\hline CMS (kg/d) & 22,5532 & 2,9804 & $-0,0957$ & $-0,2367$ & 0,3122 \\
\hline CMS (\%peso/d) & 3,2926 & 1,0920 & & $-0,0574$ & 0,3046 \\
\hline CFDN (kg/d) & 7,8444 & $-2,3604$ & & & 0,3438 \\
\hline CFDN (\% peso/d) & 1,2256 & & & & - \\
\hline DFDN (\%) & 46,2327 & $-14,3700$ & & & 0,3080 \\
\hline NDT (\% MS) & 51,3476 & 18,0811 & 0,4333 & $-0,5381$ & 0,0824 \\
\hline CNDT (kg/d) & 12,6425 & 4,8000 & & $-0,2373$ & 0,1471 \\
\hline PL (kg/d) & 32,9241 & $-8,8731$ & $-0,2617$ & & 0,4370 \\
\hline PLC (kg/d) & 30,0042 & $-7,2054$ & $-0,2048$ & & 0,4167 \\
\hline Gor $(\%)$ & 3,7050 & 0,5003 & & $-0,0310$ & 0,0747 \\
\hline Ptn $(\%)$ & 3,5717 & 0,3289 & $-0,0088$ & & 0,5261 \\
\hline
\end{tabular}

FOR representa variável dummy (silagem de milho = 0 , cana-de-açúcar $=1$ ).

CMS = consumo de matéria seca; CFDN = consumo de fibra em detergente neutro; DFDN = digestibilidade da FDN; NDT = nutrientes digestíveis totais; CNDT = consumo de NDT; PL = produção de leite; PLC = produção de leite corrigida para 3,5\% de gordura; Gor = teor de gordura do leite; Ptn = teor de proteína do leite. 
Tabela 4 - Estimativas dos parâmetros de regressão ( $\mathrm{Y}=\mathrm{B}_{0}+\mathrm{B}_{1} \cdot \mathrm{FOR}+\mathrm{B}_{2} \cdot \mathrm{X}+\mathrm{B}_{3}$.X. FOR) do efeito do teor de FDNnf na dieta (\%) sobre o consumo, digestibilidade e desempenho de vacas leiteiras recebendo dietas à base de silagem de milho ou cana-de-açúcar

\begin{tabular}{|c|c|c|c|c|c|}
\hline \multirow[t]{2}{*}{ Variável dependente (Y) } & \multicolumn{4}{|c|}{ Estimativa dos parâmetros } & \multirow[t]{2}{*}{$\mathrm{R}^{2}$} \\
\hline & $B_{0}$ & $B_{1}$ & $B_{2}$ & $B_{3}$ & \\
\hline CMS (kg/d) & 19,5977 & $-3,0494$ & & 0,2013 & 0,1648 \\
\hline CFDN (kg/d) & 6,2637 & $-2,1095$ & 0,1238 & & 0,4920 \\
\hline CFDN (\% peso/d) & 1,0553 & $-0,3371$ & 0,0208 & & 0,4858 \\
\hline DFDN (\%) & 46,2327 & $-14,3700$ & & & 0,3080 \\
\hline PL (kg/d) & 24,8421 & $-6,1631$ & & & 0,3733 \\
\hline PLC $(\mathrm{kg} / \mathrm{d})$ & 23,6788 & $-5,0843$ & & & 0,3612 \\
\hline Gor (\%) & 3,7050 & $-0,4229$ & & 0,0266 & 0,0760 \\
\hline Ptn $(\%)$ & 3,4353 & 0,2099 & $-0,0106$ & 0,0176 & 0,5483 \\
\hline
\end{tabular}

FOR representa variável dummy (silagem de milho = 0, cana-de-açúcar $=1$ ).

CMS = consumo de matéria seca CFDN = consumo de fibra em detergente neutro; DFDN = digestibilidade da FDN; NDT = nutrientes digestíveis totais; CNDT = consumo de NDT; PL = produção de leite; PLC = produção de leite corrigida para 3,5\% de gordura; Gor = teor de gordura do leite; Ptn = teor de proteína do leite.

apresentados sobre a necessidade de discriminação da FDN para melhor avaliação do seu impacto sobre o consumo.

A discriminação da fibra em FDNf e FDNnf permitiu identificar as diferenças físicas e químicas entre as fontes de forragens e não-forragens, o que não foi possível quando expressa sem discriminação (FDN). Quando o teor de fibra na dieta é expressa sem discriminação (FDN) os efeitos antagônicos entre as fontes (silagem de milho vs cana-deaçúcar; forragem vs não forragem) anulam os efeitos da fibra sobre o consumo, digestibilidade e desempenho animal.

Para compreender os mecanismos pelos quais a FDN da cana-de-açúcar apresenta maior efeito de repleção ruminal (RRt), utilizou-se o modelo descrito originalmente por Waldo et al. (1972). Para estimação do RRt, utilizaram-se valores médios de fração potencialmente digestível da FDN (FDNpd), fração indigestível da FDN (FDNi) e taxa de degradação da FDNpd (Kd) da cana-de-açúcar e silagem de milho, obtidos de três publicações (Cabral et al., 2000; Campos et al., 2006; Casali et al., 2008). Valores de kd da silagem de milho e cana-de-açúcar foram de 0,028 e 0,032/hora, respectivamente. Ressalta-se que em todos os trabalhos avaliaram-se as duas fontes conjuntamente. Considerou-se taxa de passagem de 0,02/hora para ambas as frações. A repleção ruminal total da FDN (RRt-FDN) foi decomposta para os efeitos de FDNpd (RRt-FDNpd) e FDNi (RRt-FDNi) (Figura 1).

O maior RRt-FDN da cana-de-açúcar (34,9 h) em relação à silagem de milho (29,0h) é reflexo de sua maior fração de FDNi (51,8\% da FDN vs 28,0\% da FDN) e não da menor taxa de degradação da FDNpd, pois ao contrário, mostrou-se superior (0,032 vs 0,028/hora). Assim, embora o RRt-FDNpd seja menor na cana-de-açúcar devido à menor fração FDNpd e maior kd, o maior RRt-FDNi mais que compensou, refletindo em ampliação do RRt-FDN. O maior efeito relativo de repleção
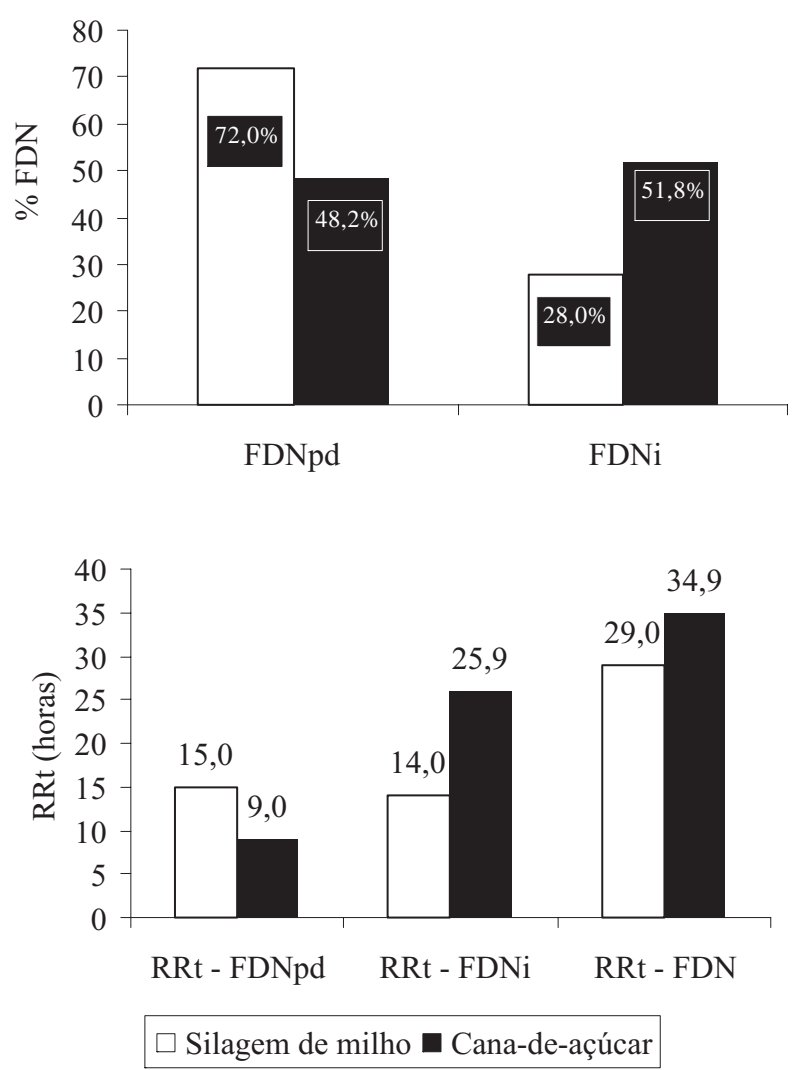

Figura 1 - Fração potencialmente digestível(FDNpd) e indigestível (FDNi) da FDN, taxa de digestão (kd) da FDNpd de silagem de milho e cana-de-açúcar (A). Estimativa do efeito de repleção ruminal (RRt) da FDNpd, FDNi e FDN (FDNpd + FDNi) para silagem e milho e cana-deaçúcar, segundo o modelo proposto por Waldo et al. (1972), considerando Kp de 0,02/hora (B).

ruminal da FDNi em relação a FDNpd é explicado pela dinâmica de desaparecimento. O desaparecimento ruminal da fração FDNpd é influenciado pela digestão e passagem, enquanto que a fração FDNi apenas pela passagem. 
Entretanto, ressalvas devem ser feitas em relação ao modelo utilizado. Como o modelo original de Waldo et al. (1972) não considera o efeito de latência e assume a mesma taxa de passagem para as frações FDNi e FDNpd não degradadas, as estimativas poderão não representar o real efeito de RRt. Reconhecidamente, em determinados alimentos o processo de degradação da fração FDNpd inicia-se somente quando cumpridas etapas iniciais ligadas à hidratação do substrato, à remoção de possíveis substâncias bacteriostáticas por solubilização e a efetiva colonização da partícula pelas bactérias ruminais (fase de latência) (Vieira \& Fernandes, 2006). Portanto, possíveis diferenças na fase de latência entre cana-de-açúcar e silagem de milho também podem explicar os efeitos de repleção ruminal.

Lund et al. (2007) propuseram um modelo para estimar a repleção ruminal da fração FDNpd e FDNi adaptado do modelo bi-compatimental proposto por Allen \& Mertens (1988), para demonstrar que a FDNpd é retida seletivamente no rúmen diferentemente da FDNi. Ao analisar a cinética de fibra de 11 forragens pelo método in vivo de pool e fluxo, os autores observaram maiores taxas de passagem da FDNi em relação à FDNpd não degradada. Além disso, observaram que a retenção seletiva da FDNpd foi maior que a FDNi. As partículas da FDNi no ambiente ruminal apresenta-se com menor tamanho, maior densidade, e portanto, sob menor efeito de retenção pelos gazes no saco dorsal do rúmen, aumentando-se a probabilidade de passagem pelo orifício retículo-omasal.

O efeito antagônico na resposta do teor dietético de FDNnf sobre o consumo de matéria seca em relação ao teor de FDNf deve-se às diferenças na digestibilidade e na efetividade física da FDN entre forragens e alimentos não forragens ricos em fibra. Alimentos como a casca de soja e farelo de glúten de milho-21\% apresentam elevada digestibilidade da FDN em razão da menor lignificação e menor efetividade física. Desta forma, apresentam maior taxa de degradação da FDNpd e maior taxa de passagem das frações FDNpd não degradada e FDNi, o que reduz o efeito de repleção ruminal em relação às forragens. Embora a casca de caroço de algodão contenha fibra de baixa digestibilidade devido ao alto teor de lignina (Van Soest, 1994), em diversos estudos foram observados aumentos no consumo de matéria seca em vacas leiteiras quando substitui forragens, em razão do menor tamanho de partícula, o que aumenta a taxa de passagem (Coppock et al., 1987; Hall \& Akinyode, 2000; Assis, 2005).

A digestibilidade da FDN não foi afetada pelo aumento no teor de FDN, independente da fonte de forragem ou da forma como é expressa (FDN, FDNf e FDNnf) (Tabela 2).
Observou-se apenas menor $(\mathrm{P}<0,05)$ DFDN para as dietas à base de cana-de-açúcar em relação à silagem de milho. A ausência de efeito pode ser explicada pelo mecanismo de competição entre digestão e passagem no ambiente ruminal (Van Soest, 1994). Com aumento no teor de FDN na dieta espera-se normalmente redução na digestão da fração potencialmente digestiva da MS da dieta. Todavia, a retenção seletiva ruminal tende a aumentar com aumento no teor de FDN como um mecanismo natural de compensação, aumentando a probabilidade de digestão da FDN.

O teor de NDT na dieta não foi afetado com o aumento no teor de FDN (\%MS) (Tabela 2). Todavia, quando discriminado em FDNf observou-se redução com aumento do teor de FDNf em dietas à base de cana-de-açúcar (0,105\% de NDT para cada $1 \%$ no teor de FDNf) e aumento $(0,433 \%$ de NDT para cada $1 \%$ no teor de FDNf) em dietas com silagem de milho (Tabela 3). Este efeito antagônico pode ser explicado, pelo menos parcialmente, pela elevada fração indigestível da FDN da cana-de-açúcar. Contrariamente, o teor de NDT na dieta aumentou com aumento no teor de FDNnf na mesma magnitude $(0,2804 \%$ de NDT para cada $1 \%$ no teor de FDNnf) entre as forragens, possivelmente, em razão da elevada digestibilidade da FDN observada na maiorias das fontes de FDN não forragem avaliadas (Tabela 4).

O efeito do aumento no teor de FDN sobre o consumo de NDT (CNDT, kg/dia) é reflexo dos efeitos sobre o consumo de matéria seca e teor de NDT. Neste sentido, observou-se redução $(\mathrm{P}<0,05)$ no CNDT com aumento no teor de FDN na mesma magnitude (26,12 gramas de NDT para cada 1\% no teor de FDN) entre as forragens (Tabela 2). Todavia, quando discriminado em FDNf observou-se redução $(\mathrm{P}<0,05)$ apenas em dietas à base de cana-deaçúcar (237,3 g de NDT para cada 1\% no teor de FDNf) (Tabela 3). Contrariamente, o CNDT aumentou $(\mathrm{P}<0,05)$ com o aumento no teor de FDNnf na dieta com cana-de-açúcar (122 g de NDT para cada 1\% no teor de FDNnf), mas reduziu $(\mathrm{P}<0,05)$ em dietas com silagem de milho (66,8 g de NDT para cada $1 \%$ no teor de FDNnf) (Tabela 4).

A produção de leite não corrigida (PL) e corrigida para $4 \%$ de gordura ( $\mathrm{PLC}$ ) aumentaram $(\mathrm{P}<0,05)$ com aumento no teor de FDN na mesma magnitude (251,1 e 189,8 gramas de leite para cada $1 \%$ no teor de FDN) entre as forragens (Tabela 2). Todavia, quando discriminado em FDNf observou-se redução $(\mathrm{P}<0,05)$ com aumento no teor de FDNf (261,7 e 204,4 gramas de leite para cada 1\% no teor de FDNf) (Tabela 3). Não houve efeito do teor de FDNnf sobre a PL e PLC (Tabela 4).

$\mathrm{O}$ teor de gordura no leite foi afetado apenas com o aumento do teor de FDNf e FDNnf nas dietas com cana-deaçúcar. Aumento no teor de FDNf reduziu $(\mathrm{P}<0,05)$ o teor 
de gordura (0,031\% de gordura para cada $1 \%$ de FDNf) (Tabela 3) possivelmente, em razão da menor digestibilidade da FDN na cana-de-açúcar, o que pode reduzir a produção ruminal de acetato e butirato, precursores de ácidos graxos de cadeia curta e média na glândula mamária (Grummer, 1991). Por outro lado, o aumento no teor de FDNnf aumentou $(\mathrm{P}<0,05)$ o teor de gordura $(0,0266 \%$ de gordura para cada $1 \%$ de FDNnf) (Tabela 4$)$.

O teor de proteína do leite $(\mathrm{Ptn})$ reduziu $(\mathrm{P}<0,05)$ com aumento no teor de FDN com maior magnitude nas dietas com silagem de milho $(0,0229 \%$ de Ptn para cada $1 \%$ de FDN) em relação às dietas com cana-de-açúcar $(0,004 \%$ de Ptn para cada $1 \%$ de FDN) (Tabela 2). Este comportamento provavelmente se deve ao menor teor de CNF da silagem de milho, o que causou maior redução desta fração na dieta com aumento de FDN. Como a fração CNF constitui substrato quase que completamente digestível no rúmen, sua redução apresenta maiores impactos negativos sobre a síntese de proteína microbiana ruminal, principal fonte de aminoácidos digestíveis no intestino delgado em animais ruminantes. Quando a fibra foi discriminada em FDNf observou reduções $(\mathrm{P}<0,05)$ no teor de $\mathrm{Ptn}$ na mesma magnitude entre as dietas $(0,0088 \%$ de Ptn para cada $1 \%$ de FDNf) (Tabela 3). Todavia, quando expressa em FDNnf, o teor de Ptn do leite aumentou nas dietas com cana-de-açúcar ( $0,007 \%$ de Ptn para cada $1 \%$ de FDNnf) e reduziu nas dietas com silagem de milho $(0,0106 \%$ de Ptn para cada $1 \%$ de FDNnf) (Tabela 4).

De maneira semelhante ao observado nas frações de FDN, o impacto da proporção de lignina na FDN sobre o consumo, digestibilidade e desempenho animal depende da fonte de forragem. $\mathrm{O}$ aumento na fração lignina:FDN na dieta causou maior redução no consumo de matéria seca (kg/dia) em dietas com cana-de-açúcar (503,8 gramas de MS para cada 1\% de lignina:FDN) em relação à silagem de milho (111,1 gramas de MS para cada 1\% de lignina:FDN) (Tabela 5). Desta forma, também se evidencia a heterogeneidade da fração lignina quanto à sua composição e seu impacto sobre a cinética de digestão e passagem ruminal entre as forragens (Van Soest, 1994).

Reconhecidamente, a lignina constitui elemento chave que limita a digestibilidade da FDN, mas a ligação cruzada entre lignina os polissacarídeos da parece celular (notadamente hemicelulose) e o ácido ferrulico são prérequisitos para a ocorrência deste efeito (Jung \& Allen, 1995). Assim, a composição da lignina influência seu impacto sobre a digestibilidade e consumo, indicando a necessidade de discriminação qualitativa para sua utilização mais eficaz em modelos de predição de digestão e consumo.

Segundo Van Soest (1994), a fração lignina exerce maior efeito sobre a digestibilidade do que sobre o consumo. Todavia, observou-se o contrário, com efeito negativo $(\mathrm{P}<0,05)$ do aumento da fração lignina:FDN sobre o consumo de matéria seca, fibra em detergente neutro e nutrientes digestíveis totais, mas efeito positivo $(\mathrm{P}<0,05)$ sobre a DFDN e efeito nulo sobre o teor de NDT da dieta (Tabela 5).

Embora a fração lignina:FDN seja utilizado como preditor da indigestibilidade da fração FDN (Weiss et al., 1992; Detmann et al., 2004), o efeito positivo sobre a DFDN pode explicado pelo mecanismo de competição entre digestão e passagem ruminal, descrito anteriormente. Aumento na fração lignina:FDN reduz o consumo pelo maior efeito de repleção ruminal da fração FDNi. Como os processos de passagem e digestão são tempo-dependente, a maior retenção seletiva amplia a probabilidade de digestão da fração FDNpd.

Tabela 5 - Estimativas dos parâmetros de regressão ( $\mathrm{Y}=\mathrm{B}_{0}+\mathrm{B}_{1} \cdot \mathrm{FOR}+\mathrm{B}_{2} \cdot \mathrm{X}+\mathrm{B}_{3} \cdot \mathrm{X}$. FOR) do efeito da relação lignina:FDN (\%) na dieta sobre o consumo, digestibilidade e desempenho de vacas leiteiras recebendo dietas à base de silagem de milho ou cana-de-açúcar

\begin{tabular}{|c|c|c|c|c|c|}
\hline \multirow[t]{2}{*}{ Variável dependente (Y) } & \multicolumn{4}{|c|}{ Estimativa dos parâmetros } & \multirow[t]{2}{*}{$\mathrm{R}^{2}$} \\
\hline & $B_{\mathrm{o}}$ & $B_{1}$ & $B_{2}$ & $B_{3}$ & \\
\hline CMS (kg/d) & 20,9290 & 4,6120 & $-0,1111$ & $-0,3927$ & 0,3260 \\
\hline CFDN (kg/d) & 8,5703 & & $-0,0604$ & $-0,1678$ & 0,4069 \\
\hline CFDN (\% peso/d) & 1,4291 & & $-0,0089$ & $-0,0273$ & 0,3890 \\
\hline DFDN (\%) & 42,2464 & $-14,8944$ & 0,3328 & & 0,3359 \\
\hline PL (kg/d) & 26,6584 & & $-0,2725$ & & 0,1253 \\
\hline PLC (kg/d) & 26,2342 & $-4,7482$ & $-0,2133$ & & 0,4688 \\
\hline Gor (\%) & 3,8008 & 0,7056 & $-0,0080$ & $-0,0612$ & 0,1064 \\
\hline Ptn (\%) & 3,3002 & 0,4200 & & & 0,5052 \\
\hline
\end{tabular}


De maneira geral, o efeito da DFDN foi maior sobre a digestibilidade da dieta e menor sobre o consumo e desempenho animal, em relação às frações de FDN e a razão lignina:FDN. O consumo de matéria seca ( $\mathrm{kg} / \mathrm{dia}$ ) reduziu $(\mathrm{P}<0,05)$ independentemente da fonte de forragem $(15,21$ g para cada $1 \%$ de CDMS) (Tabela 6). Da mesma forma, a PL e PLC reduziram $(\mathrm{P}<0,05) 56$ e 33,5 g de leite para cada $1 \%$ de aumento na DFDN (Tabela 6), provavelmente devido à redução no consumo de matéria seca. Os teores de gordura e proteína do leite não foram afetados pela DFDN (Tabela 6).

Segundo Oba \& Allen (1999), a digestibilidade in vivo da FDN apresenta baixa correlação com o consumo de matéria seca, pois seu efeito é confundido pelos diferentes tempos de retenção ruminal, sendo mais adequadas as medições in vitro ou in situ. Além disso, o aumento na fração FDNpd resulta em incremento da digestibilidade da FDN, mas aumenta o tempo em que as partículas de FDNpd e FDNi ficam retidas aos gases em posição dorsal no rúmen, reduzindo a possibilidade de passagem da FDNpd não digerida e da FDNi pelo orifício retículoomasal (Allen, 1996; Allen, 2000).

$\mathrm{O}$ teor de NDT aumentou $(\mathrm{P}<0,05)$ com aumento na DFDN com maior magnitude nas dietas com silagem de milho $(0,4966 \%$ de NDT para cada $1 \%$ da DFDN) em relação às dietas com cana-de-açúcar $(0,20324 \%$ de NDT para cada $1 \%$ da DFDN) (Tabela 6). Como a DFDN é um dos componentes do NDT, a maior fração de FDN da silagem de milho em relação à cana-de-açúcar explica o maior impacto da DFDN sobre o teor de NDT de dieta contendo silagem de milho.

Tabela 6 - Estimativas dos parâmetros de regressão ( $\mathrm{Y}=\mathrm{B}_{0}+\mathrm{B}_{1} \cdot \mathrm{FOR}+\mathrm{B}_{2} \cdot \mathrm{X}+\mathrm{B}_{3} \cdot \mathrm{X}$. FOR) da DFDN da dieta sobre o consumo, digestibilidade e desempenho de vacas leiteiras recebendo dietas à base de silagem de milho ou cana-de-açúcar

\begin{tabular}{|c|c|c|c|c|c|}
\hline \multirow[t]{2}{*}{ Variável dependente (Y) } & \multicolumn{4}{|c|}{ Estimativa dos parâmetros } & \multirow[t]{2}{*}{$\mathrm{R}^{2}$} \\
\hline & $B_{\mathrm{o}}$ & $B_{1}$ & $B_{2}$ & $B_{3}$ & \\
\hline CMS (kg/d) & 20,3008 & $-1,1057$ & $-0,01521$ & & 0,0622 \\
\hline CMS (\%peso/d) & 3,2926 & & & & - \\
\hline CFDN (kg/d) & 7,8444 & $-2,3604$ & & & 0,3438 \\
\hline CFDN (\% peso/d) & 1,3214 & $-0,3793$ & & & 0,3298 \\
\hline NDT (\% MS) & 41,7698 & 19,0332 & 0,4966 & $-0,2934$ & 0,3911 \\
\hline CNDT (kg/d) & 11,3255 & & 0,0305 & & 0,0581 \\
\hline PL (kg/d) & 27,4299 & $-6,9674$ & $-0,0560$ & & 0,3876 \\
\hline PLC (kg/d) & 25,2273 & $-5,5656$ & $-0,0335$ & & 0,3685 \\
\hline Gor $(\%)$ & 3,6705 & & & & - \\
\hline Ptn (\%) & 3,3002 & 0,4200 & & & 0,5052 \\
\hline
\end{tabular}

FOR representa variável dummy (silagem de milho $=0$, cana-de-açúcar $=1$ ).

CMS = consumo de matéria seca; CFDN = consumo de fibra em detergente neutro; DFDN = digestibilidade da FDN; NDT = nutrientes digestíveis totais; CNDT = consumo de NDT; PL = produção de leite; PLC = produção de leite corrigida para 3,5\% de gordura; Gor = teor de gordura do leite; Ptn = teor de proteína do leite.

\section{Conclusões}

O efeito do teor de fibra em detergente neutro e de sua proporção de lignina sobre o consumo, a digestibilidade dos nutrientes e o desempenho animal depende da fonte utilizada, os quais refletem as diferenças químicas e físicas entre estes componentes. Dessa forma, recomenda-se a discriminação qualitativa das frações fibra em detergente neutro e lignina para sua utilização eficaz em modelos de predição de consumo, digestão e desempenho de vacas leiteiras.

\section{Referências}

ALLEN, M.S. Physical constraints on voluntary intake of forages by ruminants. Journal of Animal Science, v.74, p.3063-3075, 1996.

ALLEN, M.S. Effects of diet on short-term regulation of feed intake by lactating dairy cattle. Journal of Dairy Science, v.83, p.1598-1624, 2000.
ALLEN, M.S.; MERTENS, D.R. Evaluating constraints on fiber digestion by rumen microbes. Journal of Nutrition, v.118, p.261-270, 1988.

ASSIS, A.J. Casca de soja e casca de algodão em dietas de vacas em lactação. 2005. 72f. Tese (Doutorado em Zootecnia)Universidade Federal de Viçosa, Viçosa, MG.

DRAPER, N.; SMITH, H. Applied regression analysis. New York: John Willey \& Sons, 1966. 407p.

CABRAL, L.S.; VALADARES FILHO, S.C.; MALAFAIA, P.A.M. Frações de carboidratos de alimentos volumosos e suas taxas de degradação estimadas pela técnica de produção de gases. Revista Brasileira de Zootecnia, v.29, p.2087-2098, 2000.

CASALI, A.O.; DETMANN, E.; VALADARES FILHO, S.C. et al Influência do tempo de incubação e do tamanho de partículas sobre os teores de compostos indigestíveis em alimentos e fezes bovinas obtidos por procedimentos in situ. Revista Brasileira de Zootecnia, v.37, p.335-342, 2008

CAMPOS, P.R.S.S.; VALADARES FILHO, S.C.; CECON P.R. et al. Estudo comparativo da cinética de degradação ruminal de forragens tropicais em bovinos e ovinos. Arquivo Brasileiro de Medicina Veterinária e Zootecnia, v.58, p.1181-1191, 2006.

COPPOCK, C.E.; LANHAM, J.K.; HORNER, J.T. A review of the nutritive value and utilization of whole cottonseed, cottonseed meal and associated by-products by dairy cattle. Animal Feed Science and Technology, v.18, p.89-129, 1987. 
COSTA, M.G.; CAMPOS, J.M.S.; VALADARES FILHO, S.C. et al. Desempenho produtivo de vacas leiteiras alimentadas com diferentes proporções de cana-de-açúcar e concentrado ou silagem de milho na dieta. Revista Brasileira de Zootecnia, v.34, n.6, p.2437-2445, 2005 (supl.).

DETMANN, E.; VALADARES FILHO, S.C.; HENRIQUES, L.T. et al. Estimação da digestibilidade dos carboidratos não-fibrosos em bovinos utilizando-se o conceito de entidade nutricional em condições brasileiras. Revista Brasileira de Zootecnia, v.35, p.1479-1486, 2006.

DETMANN, E.; ZERVOUDAKIS, J.T.; CABRAL, L.S. et al Validação de equações preditivas da fração indigestível da fibra em detergente neutro em gramíneas tropicais Revista Brasileira de Zootecnia, v.33, p.1866-1875, 2004.

GRUMMER, R.R. Effect of feed on the composition of milk fat. Journal of Dairy Science, v.74, p.3244-3257, 1991.

HALL, M.B.; AKINYODE, A. Cottonseed hulls: working with a novel fiber source. In: ANNUAL FLORIDA RUMINANT NUTRITION SYMPOSIUM, 11., 2000, Gainesville. Anais... Gainesville: University of Florida, 2000. p.179-186.

JUNG, H.G.; ALLEN, S. Characteristics of plant cell walls affecting intake and digestibility of forages by ruminants. Journal of Animal Science, v.73, p.2774-2790, 1995.

KRIZSAM, S.J.; RANDBY, A.T. The effect of fermentation quality on the voluntary intake of grass silage by growing cattle fed silage as sole feed. Journal of Animal Science, v.85, p.984-996, 2007.

LUND, P.; WEISBJERG, M.R.; HVELPLUND, T. Digestible NDF is selectively retained in the rumen of dairy compared to indigestible NDF. Animal Feed Science and Technology, v.134, p.1-17, 2007.

MAGALHÃES, A.L.R.; CAMPOS, J.M.S; CABRAL, L.S. et al. Cana-de-açúcar em substituição à silagem de milho em dietas para vacas em lactação: parâmetros digestivos e ruminais. Revista Brasileira de Zootecnia, v.35, p.591-599, 2006.

MERTENS, D.R. Predicting intake and digestibility using mathematical models of ruminal function. Journal of Dairy Science, v.64, p.1548-1558, 1987.

OBA; M.; ALLEN, M. Evaluation of the importance of the digestibility of neutral detergent fiber from forage: effects on dry matter intake and milk yield of dairy cows. Journal of Dairy Science, v.82, p.589-596, 1999.

OLIVEIRA, A.S.; CAMPOS, J.M.S.; VALADARES FILHO, S.C. et al. Substituição do milho por casca de café ou de soja em dietas para vacas leiteiras: consumo, digestibilidade dos nutrientes, produção e composição do leite. Revista Brasileira de Zootecnia, v.36, n.4, p.1172-1182, 2007.

PAULINO, M.F.; DETMANN, E.; VALADARES FILHO, S.C. Suplementação animal em pasto: energética ou protéica. In: SIMPÓSIO SOBRE MANEJO ESTRATÉGICO DA PASTAGEM, 3., 2006, Viçosa, MG. Anais... Viçosa, MG: DZO-UFV, 2006. p.359-392.

PEREIRA, E.S.; QUEIROZ, A.C.; PAULINO, M.F. et al. Determinação das frações protéicas e de carboidratos e taxas de degradação in vitro da cana-de-açúcar, da cama de frango e do farelo de algodão. Revista Brasileira de Zootecnia, v.29, p.1887-1893, 2000.

PINA, D.S.; VALADARES FILHO, S.C.; VALADARES, R.F.D. et al. Consumo e digestibilidade aparente total dos nutrientes, produção e composição do leite de vacas alimentadas com dietas contendo diferentes fontes de proteína. Revista Brasileira de Zootecnia, v.35, n.4, p.1543-1551, 2006.

SMITH, L.W.; GOERING, H.K.; GORDON, C.H. Relationships of forage compositions with rates of cell wall digestion and indigestibility of cell walls. Journal of Dairy Science, v.55, p.1140-1147, 1972.

SOUZA, S.M. Farelo de glúten de milho na alimentação de vacas em lactação. 2007. 53f. Dissertação (Mestrado em Zootecnia) - Universidade Federal de Viçosa, Viçosa, MG.

Van SOEST, P.J. Symposium on factors influencing the voluntary intake of herbage by ruminants: voluntary intake in relation to chemical composition and digestibility. Journal of Animal Science, v.24, p.834-843, 1965.

Van SOEST, P.J. Nutritional ecology of the ruminants. 2.ed. Ithaca: Cornell University Press, 1994. 476p.

VASQUEZ, O.P.; SMITH, T.R. Factors affecting pastures intake and total dry matter intake in grazing dairy cows. Journal of Dairy Science, v.83, p.2301-2309, 2000.

VIEIRA, R.A.; FERNANDES, A.M. A importância de estudos quantitativos associados à fibra para a nutrição e a alimentação de ruminantes. In: REUNIÃO ANUAL DA SOCIEDADE BRASILEIRA DE ZOOTECNIA, 43., 2006, João Pessoa. Anais... João Pessoa: SBZ, 2006. p.258-290.

WALDO, D.R.; SMITH, L. W.; COX, E.L. Model of cellulose disappearance from the rumen Journal of Dairy Science, v.55, p.125-129, 1972

WEISS, W.P.; CONRAD, H.R.; St-PIERRE, N.R. A theoreticallybased model for predicting total digestible values of forages and concentrates. Animal Feed Science and Technology, v.39, p.95-110, 1992. 